\title{
Visiones y prácticas políticas de los Arakbut
}

\section{Political Visions and Practices of the Arakbut}

\author{
Thomas Moore \\ https://orcid.org/0000-0002-9820-9317 \\ Centro Eori de Investigación y Promoción Regional \\ tm1854@gmail.com
}

Recibido:03/04/2019 - Aceptado: 02/09/2019 - Publicado: 12/03/2021

\section{Resumen}

El autor analiza los conceptos y las prácticas de la política entre los arakbut del sur de Madre de Dios, Perú, en el contexto de las adaptaciones introducidas a partir del inicio de los contactos permanentes con la sociedad nacional, desde la década del cincuenta hasta la actualidad. Basado en su trabajo de campo con entrevistas con ancianos que vivían en tiempos pre-contacto, además de sus observaciones a través de los años, demuestra cómo los arakbut combinan su sistema político tradicional, similar al modelo de Clastres, con organizaciones y prácticas de interacción con el Estado peruano según la normatividad y prácticas de los no indígenas, en una forma que les permite sostener su identidad y estilo de vida.

\section{Palabras Claves}

Arakbut; política; modelo de Clastres; organizaciones indígenas; elecciones.

\section{Abstract}

The author analyzes the political concepts and practices of the Arakbut of southern Madre de Dios, Peru, with the adaptation adopted since entering into permanent contact with the national society in the decade of the 1950s until today. Based on field work, including interviews with elders alive in pre-contact times, and personal observations since that time, he shows how the Arakbut have combined their traditional political system, similar to the Clastres model, with organizations and practices that allow them to interact with national society actors and processes in a manner that allows them to maintain their identity and lifestyle.

\section{Keywords}

Arakbut; politics; Clastres model; indigenous organizations; elections.

Citar como: More T. (2021). Visiones y Prácticas Políticas de los Arakbut. Revista de antropología núm. 8: 17 - 36. http://dx.doi.org/10.15381/antropologia.v0i8.19806 
En este aporte reúno material tanto de mis investigaciones de campo realizadas durante dos años entre los arakbut del sur de Madre de Dios, Perú, como mis observaciones de ellos a través de sucesivas visitas en los ańos posteriores. Mi intención es recoger tanto las visiones como las prácticas en torno a lo político desde el momento de sus primeros contactos permanentes con la sociedad nacional en la década de 1950 hasta la actualidad.

Nuestra visión segmentaria occidental, que separa lo político de lo económico, lo religioso y lo sociocultural agrede a la visión holística e integral de los mismos arakbut, la cual será ajeno para la mayoría de nuestros lectores. Mi propósito es que estos apuntes sirvan a los arakbut como interpretación no arakbut de su propia experiencia en torno a su relación con el poder y el Estado.

\section{El ENFOQUe TeÓRICO}

En mi formación universitaria de posgrado en antropología, me inspiró la visión de Stanley Diamond (1993), quien encontró en las sociedades primitivas la respuesta a la crisis de la civilización occidental. Diamond mantiene que "en las sociedades primitivas, las funciones y roles principales del liderazgo son comunales y tradicionales, no políticas ni seglares" (p. 135). Consideró el liderazgo "situacional y basado en habilidades" (p. 135). Esa visión fue la que más me orientó para realizar mis investigaciones en un pueblo amazónico con poca historia de articulación con Estados nacionales, como son los arakbut.

También tuvieron influencia en mis reflexiones sobre las relaciones de los pueblos amazónicos con su entorno de la economía y política global, el enfoque sobre el etnocidio, iniciado por Jaulin (1970), la perspectiva de Clastres (1974), sobre la que tendré más que decir líneas abajo, y el enfoque marxista sobre los modos de producción, tales como la discusión de Hindess y Hirst (1975) sobre el comunismo primitivo, el comunismo y el Estado, y especialmente el de Meillassoux (1977) con su discusión sobre la dialéctica de la igualdad y las premisas de la desigualdad. Sin embargo, cuando fui al campo ya había decidido orientarme por la evidencia empírica encontrada allí y no preconcebir mis interpretaciones en base a las discusiones teóricas vigentes. He intentado ser fiel a esa decisión, aunque mis interpretaciones obviamente reflejan la posición teórica que mantengo y expreso en la discusión que sigue.

Mi hipótesis fue que, al no forzar conclusiones mecánicas a través de marcos teóricos occidentales, los arakbut, como sociedad primitiva, me darían luces que me permitieran transcender, personalmente, la crisis de la civilización occidental. Así lo anticipó Diamond y, efectivamente, así ha resultado. 


\section{ARAKBUt, HARAKBUT Y AMARAKAERI}

Los arakbut hablan el idioma harakbut ${ }^{1}$ - pronunciado con aspiración inicial-, que es el nombre del pueblo mayor. Esta parcialidad, ahora la más numerosa, se autodenomina arakbut -con oclusiva glotal inicial. Los arakbut eran conocidos antes como amarakaeri, término que ellos no consideran peyorativo sino aplicado de fuera y por tanto no propio (Gray 2003, p. 385).

El término "maracaires" aparece en la literatura por primera vez en el informe de Olivera (1907, p. 421). Según mis interlocutores mayores, ese término se originó con el nombre aplicado por miembros de la parcialidad sapiteri, a una maloca arakbut ubicada en el alto río Karene como amaraka'otéakwe, (amaraka $=$ masacre + 'ote $=$ loma $+' a k=$ maloca $+w e=$ lugar, o sea, el lugar de la maloca de la loma de la masacre). No había memoria sobre la masacre referida. De allí que las otras parcialidades harakbut comenzaron a llamar amarakaeri no solo a los moradores de esa maloca y sus descendientes, sino a la parcialidad con todas sus malocas. Aparte de los arakbut hay seis otras parcialidades harakbut y posiblemente una más que desapareció antes de mi llegada al campo por primera vez (Moore, 2003, p. 75). Estas son amaiweri o pukirieri, de la comunidad de Kotsimba; arasaeri, de la comunidad Arasaeri; kisa’beri, de la comunidad Boca Ishiri; sapiteri, ahora en la comunidad de Boca Ishiri y en el río Pukiri; toyeri, con un representante en la comunidad de Shintuya y otros en los centros urbanos de Laberinto y Puerto Maldonado; y wachiperi, de las comunidades Queros, Santa Rosa de Huacaria, Shintuya, Diamante y Puerto Azul.

Mi trabajo de campo (1973-1975) abarcó todo el pueblo mayor harakbut y tenía como objetivo reconstruir su cultura antes del contacto mediante entrevistas sistemáticas con las personas mayores que habían llegado a la condición de adultos con familias propias antes de los contactos producidos en la década del cincuenta. Centré mis investigaciones en la aldea entonces más aislada, Puerto Alegre, de la actual comunidad nativa de Puerto Luz. Casi todos mis interlocutores originales han fallecido, motivo por el cual no mencionaré sus nombres por respeto al tabú arakbut que prohíbe pronunciar los nombres de los difuntos.

\section{LA POLÍTICA DE LOS ARAKBUT TRADICIONALES}

Los Arakbut eran y siguen siendo un pueblo igualitario, sin distinciones de clase social ni de rango. El papel social al interior de la comunidad se distingue por

\footnotetext{
${ }^{1}$ No se han comprobado todavía vínculos con alguna de las principales familias lingüísticas, aunque hay proyecciones de una posible relación con los idiomas katukina y katawixí del noroeste de Brasil (Adelaar, 2000, 2007). Los hablantes del idioma harakbut fueron el último pueblo indígena de Madre de Dios en entrar en contacto o relaciones permanentes con la sociedad nacional hacia mediados del siglo XX (FENAMAD, 2015; Moore, 2015). Sin embargo, ahora están apareciendo dos otros pueblos indígenas en contacto inicial, los llamados mashco piro, un pueblo que habla un idioma arawak del Parque Nacional del Manu y las cuencas de los ríos Amigos y de las Piedras, y los murunahua del norte de la región Madre de Dios y este de la región Ucayali (Huertas, 2002, 2003, 2010; Parellada, 2007).
}

Revista de antropología (marzo 2021) núm. 8: 19 - 36. 
edad y sexo y la ubicación en el sistema de parentesco. Si bien con la economía del oro unos pocos arakbut manejan importantes recursos monetarios, esto aún no se refleja en las relaciones sociales como mayor rango o prestigio más allá de su grupo de parentesco y aliados políticos.

En dicho sistema de parentesco patrilineal predomina la filiación a uno de los siete clanes exógamicos y totémicos (Moore, 2003). Cuando les he preguntado en diferentes ocasiones sobre las preferencias en la distribución de carne y otras dádivas o interacciones recíprocas, siempre me contestan que comparten entre todos por igual. Sin embargo, mis observaciones en el campo me dejaron claro que las mujeres efectúan el reparto, primero a los fogones cuyos varones principales son del mismo clan que el marido de la repartidora, y de allí, si alcanza, a las familias de su clan y de los otros.

La población de Puerto Alegre entre 1973 y 1975 creció de 113 a 128 personas, incluyendo a los recién nacidos que todavía no tenían nombre. Hoy, Puerto Luz tiene una población de aproximadamente 800 habitantes y sería imposible compartir con todos.

Los arakbut no tenían y no tienen jefes en el sentido de autoridad y poder impositivo o de coerción. Lo que sí tenían y aún tienen son hombres llamados $w a^{\prime} i r i$, término que significa persona de prestigio. Esta condición no es hereditaria; refleja las habilidades de una persona de producir y compartir bienes entre sus paisanos por ser buen cazador, poseer numerosas chacras, tener prole numerosa y ser buen orador con habilidades de liderazgo. Puede haber uno, varios o ningún wa'iri en determinada aldea o comunidad nativa. Suelen ser shamanes, pero no siempre. En todas sus actividades el trato es igualitario y de respeto mutuo. El prestigio del wa'iri se debe a su capacidad de influir sobre los otros comuneros y facilitar su llegada al consenso sobre los temas bajo consideración política.

$\mathrm{Al}$ interior de una comunidad, no se impone la posición de una mayoría sobre la de una minoría. Por tanto, los arakbut rechazan la democracia de mayoría y buscan el consenso. La falta de consenso en casos extremos persistentes puede conducir a la separación de los sustentadores de la posición minoritaria y su independización en otra localidad de su territorio.

Un arakbut defiende a los miembros de su propio clan frente a los miembros de otros clanes en casos de agresión o ataque verbal o físico. Los que están en desacuerdo con su posición no se presentaban a la reunión en los espacios comunes fuera de los fogones al interior de la maloca o haktöne, ahora en el salón comunal. Estos espacios se tornan hervideros de conversación después de la comida nocturna. Allí se discuten las posiciones de los comuneros y se buscan consensos. Cuando el problema no se resuelve, se produce la separación de una 
facción de la comunidad y su reorganización en otro lugar. He observado esta situación en repetidas ocasiones.

En 1971, en la comunidad de Shintuya, hubo mucha tensión sobre la presencia de ganado vacuno que habían introducido los misioneros dominicos y que la mayoría de la comunidad rechazaba. Un grupo era especialmente reacio a estos animales y, cuando no podían lograr el consenso sobre el retiro de estos animales, se retiró de la comunidad y se reubicó en el lugar de la actual comunidad nativa Barranco Chico.

En otra ocasión, en 1973, en la comunidad ahora llamada Puerto Luz, un hombre del clan idsika'bo había entrado en relaciones sexuales con una mujer cuyo marido era del clan singperi. Cuando la noticia se difundió en toda la comunidad, surgió un conflicto violento entre los dos clanes. Tras varios días de discusión, la comunidad acordó por consenso la expulsión del hombre de su seno, al menos por un tiempo hasta que se superara la situación. Un año y medio después, ese mismo hombre retornó a la comunidad y se unió con otra mujer. Así, la crisis se superó y las relaciones interclánicas quedaron pacíficas.

También en 1973, hubo otro conflicto en la misma comunidad cuando varios hombres de la comunidad vecina, San José de Karene, llegaron en plan de correría para capturar mujeres. Hubo una pelea a puñetazos entre los hombres del clan de las mujeres pretendidas en Puerto Luz y los hombres de otros clanes de San José del Karene. La situación se resolvió con el rescate de las mujeres y el retiro de los hombres de San José sin ellas. Por varios años las relaciones entre las dos comunidades fueron tensas.

En 1975, los hombres de Puerto Luz del clan idsika'bo que se dedicaban a la minería aurífera propusieron al resto de la comunidad su traslado a un sitio más cercano a la desembocadura del río Karene, donde había una agencia del Banco Minero del Perú que compraba su oro y vendía artículos de primera necesidad. Otra facción se opuso porque no querían estar tan cerca de los mestizos y serranos. Tras varios días de discusión alrededor de los fogones por las tardes, los del clan singperi, convencieron a los otros de que se trasladaran a un sitio en la desembocadura del río Wasorok (Huasoroco en español) a un día de viaje del puesto del Banco Minero del Perú, medio día menos distante. Por consenso acordaron instalarse allí, dando origen al asentamiento principal actual de Puerto Luz.

Cuatro años después, hubo otro conflicto entre los clanes singperi e idsika'bu en Puerto Luz sobre la intensidad de la minería aurífera entre comuneros de la comunidad. Cuando este conflicto no pudo resolverse, los idsika'bu que insistían en mayor actividad minera, no todo el clan, se alejó del espacio de la comunidad y se estableció en la desembocadura del río Karene o Colorado, 
cerca del puesto del Banco Minero². Dos años más tarde, por conflictos con los mineros foráneos, ese grupo volvió a incorporarse al territorio de Puerto Luz.

\section{El modelo de Clastres}

Este tipo de autogobierno autónomo e igualitario prioriza el servicio de los líderes al pueblo en su conjunto antes que el dominio de él por una casta o clase que se considera de algún modo superior a los otros. Este ha sido el enfoque del antropólogo francés Pierre Clastres (1974), quien realizó su trabajo de campo entre los mbaya guaraní de la familia lingüística tupí-guaraní en Paraguay.

Para Clastres, las características más importantes del líder indígena no andino de América del Sur eran su condición de sirviente de su pueblo, no mandante de él, el uso de su poder relativo para fines humanitarios dentro de su sociedad, su capacidad oratoria y de persuasión a su pueblo hacia el consenso, y su condición de shamán o profeta para conseguir los seguidores que le permitan avanzar propuestas para el bienestar de la colectividad. Estos pueblos amerindios viven en agrupaciones (dèmes) con poblaciones limitadas, nunca más de 200 personas. Cuando no se logra el consenso en decisiones de importancia, se separan las facciones disidentes y se reestablecen en otros espacios en forma independiente. Así no se concentra ni la población ni el poder.

Algunos de sus críticos tildan a Clastres de anarquista utópico y cuestionan su modelo como impráctico y poco realista. Considero que dicho modelo es ideal y no pretende reflejar la realidad objetiva y precisa de ningún pueblo indígena concreto, y que conceptualmente es válido para algunos, aunque no todos, los pueblos amazónicos. En otras partes de la Amazonía, la arqueología y la geografía cultural demuestran la presencia de sociedades amazónicas más complejas y con los inicios de estratificación social, en las cuencas del Mamoré en Bolivia, Purús en Brasil y Ucayali en el Perú. Veo el modelo de Clastres no aplicable a esas sociedades antiguas que habían desarrollado jerarquías o clases sociales diferenciadas y que permitían la movilización de la mano de obra requerida para sus obras de infraestructura, aunque tampoco es aplicable a sus descendientes contemporáneos.

Sin embargo, otros pueblos amazónicos, que históricamente habitaban áreas más alejadas de las rutas principales de intercambio, como los arakbut, sí reúnen las características principales del modelo de Clastres, o las reunían en el momento histórico de los inicios de su interacción con la sociedad y economía política nacional y global. Además, las sostienen en aspectos importantes actualmente ${ }^{3}$.

${ }^{2}$ En ese lugar se realizó el congreso fundacional de FENAMAD, porque era neutral en los conflictos entre las diferentes comunidades arakbut.

${ }^{3}$ Para un mayor análisis del modelo de Clastres, ver los 12 artículos del dossier editado por Perrone-Moisés, Sztutman y Cardoso, en la Revista de Antropología de la Universidad de Sao Paulo (2011). 
Según un peritaje de mi autoría (FENAMAD, 2015) que la Federación Nativa del Río Madre de Dios y Afluentes (FENAMAD) presentó al Tribunal Constitucional del Perú, el territorio ancestral de los harakbut era de casi tres millones de hectáreas, entre Madre de Dios, Cusco y Puno. Siguiendo el modelo de Clastres, los harakbut en su conjunto nunca han ejercido gobernanza ni dominio político centralizado sobre ese territorio, sino que ejercían y aún ejercen el autogobierno local sobre espacios locales de él. Sin embargo, todos ellos reconocen la unidad étnica de su pueblo y la ocupación ancestral de este territorio que forma parte integral de su identidad.

Para los arakbut, el concepto de territorio es diferente de la visión de la sociedad nacional. No es visto como un bien separado de sus personas ni de su sociedad. No pueden aceptar la enajenación de una parte de su territorio, lo que les coloca en conflicto con la economía capitalista mercantil y las leyes que separan las tierras de los bosques, las aguas y el subsuelo. El valor simbólico de su territorio, wandari en su idioma, que también significa mundo, es inseparable de su ser. Distinguen y diferencian entre los objetos creados por su trabajo o propiedad individual de lo que pertenece a su clan (mayormente los bienes que se comparten con mayor frecuencia), lo que corresponde a la comunidad (los bienes e interacciones intercambiados en la colectividad), y lo que corresponde a un todo territorial, o sea su mundo conocido como pueblo (Álvarez del Castillo, 2012, p. 27). La gobernanza del territorio tiene lugar a varios niveles, sin autoridad centralizada, pero con obligaciones comunes entre todos los integrantes del pueblo que asumen como suyo dicho territorio.

Esa visión de pertenencia a su todo territorial llevó a los arakbut a proponer, en 1986, la creación legal de la Reserva Comunal Amarakaeri (RCA), que finalmente se constituyó sobre 402,335.62 hectáreas de su territorio ancestral colindante con las tierras tituladas de seis de las comunidades arakbut y una yine. Así, incorporó la mayor parte de los espacios intermedios entre dichas comunidades que no eran ocupadas por colonos ni mineros auríferos.

Gray caracteriza la gobernanza arakbut tradicional como "gobierno mínimo", con un enfoque en la toma de decisiones de la colectividad local y en la resolución de disputas (2002, pp. 270, 273, 277, 279). En su interpretación, el gobierno mínimo arakbut se ha complementado en años recientes con un modelo de "gobierno difuso", refiriéndose a los mecanismos de adaptación a los procedimientos requeridos por el Estado. Dichos conceptos, tomados de Mair (1962, pp. 61-106) me parecen más adecuados para las jerárquicas sociedades pastoriles africanas descritas por Mair que para los arakbut, pero Gray muestra correctamente los dos modelos complementarios de gobernanza desde la perspectiva de los arakbut. 
La población en las comunidades arakbut ha aumentado enormemente después de la caida demográfica que ocurrió con el contacto permanente. Ahora está asentada en ocho comunidades nativas y concentrada en áreas cercanas a las escuelas estatales. En 1968, solo había una comunidad arakbut independiente, la de la actual Puerto Luz. Los otros arakbut estaban incorporados en la misión dominica de Shintuya, ahora rodeada por la comunidad nativa del mismo nombre.

Entre 1968 y 1974, entre los arakbut de Shintuya surgieron conflictos por las muertes que ocurrían debido a la entrada de epidemias desde afuera y contra las cuales ellos no tenían resistencia inmunológica. Esta crisis provocó acusaciones de brujería contra las personas consideradas culpables de la muerte. Por tanto, en migraciones sucesivas hacia otros sectores de su territorio ancestral, las facciones arakbut de Shintuya comenzaron a alejarse de esa comunidad y del control de la misión dominica que orientaba sus vidas.

Así se constituyeron las comunidades de San José de Karene en 1968, Boca del Inambari en 1970 y de Barranco Chico en 1971 (Torralba, 2014), que ahora son comunidades nativas con reconocimiento oficial y tierras tituladas. Dos otras comunidades nativas arakbut, Masenawa y Puerto Azul, se constituyeron en la década de 1990 de escisiones similares de la comunidad de Boca del Inambari. Otra comunidad harakbut, Boca Ishiri, con parcialidades harakbut kisaberi y sapiteri se instaló en la desembocadura del río Ishiri en la misma época, procedentes de una zona del río Pukiri invadida por mineros auríferos foráneos.

Actualmente, a diferencia de la situación en años pasados, con las tierras de las comunidades nativas tituladas y los espacios externos ocupados por no indígenas, hay menos opción para la reubicación de facciones. Por ello, si bien aún suelen separarse físicamente, lo hacen al interior de la misma concentración de población en torno a escuelas y canchas de futbol en el mismo asentamiento. Como resultado, surgieron los barrios o "grupos residenciales", señalados por Pinedo (2014, pp. 119, 120).

Históricamente, los arakbut se mantenían relativamente aislados aún de las otras parcialidades harakbut, debido a las tensiones y conflictos que mayormente resultaron de correrías por mujeres y también por celos en torno a acusaciones de brujería como explicación de las enfermedades y muertes que acompañaban a las incursiones en la región de agentes de los frentes extractivos. Los brujos o brujas siempre eran de otro clan u otra parcialidad, nunca del clan o parcialidad de uno.

Pero cuando ocurrían incursiones de los frentes extractivos, como la expedición militar del Prefecto de Cuzco, Baltazar La Torre en 1873 (Göhring, 2006; Moore, 2006), todos los clanes y todas las parcialidades harakbut se movilizaron en causa común para enfrentarlo. Una situación similar ocurrió 
en agosto de 1978 cuando dos empresas de mineros auríferos habían invadido las tierras de la comunidad Boca del Inambari con el respaldo de denuncios mineros otorgados por el Ministerio de Energía y Minas. Cuando llegué allí, encontré a más de 200 hombres arakbut que habían llegado con sus familias desde todas sus comunidades para defender a sus paisanos de Boca del Inambari, no obstante que hacía pocos años hubo conflictos sobre mujeres y acusaciones de brujería entre los diferentes arakbut presentes.

Este conflicto se resolvió a medias por la intervención de representantes del Sistema Nacional de Movilización Social (SINAMOS) del gobierno militar, quienes brindaban alguna información sobre los derechos que tenían los comuneros en base a la Ley de Comunidades Nativas (Decreto Ley 22175) ante los representantes del Ministerio de Energía y Minas y los mineros, llegando a acuerdos sobre plazos de retiro de los mineros. Aunque los mineros incumplieron los plazos dados para su retiro, eventualmente esta comunidad recuperó sus tierras. Actualmente, Boca del Inambari se encuentra libre de mineros que no son comuneros.

\section{MaYor Relación CON el ESTAdo E INSERCIÓn EN LA ECONOMÍA GLOBAL}

Para la implementación de las sucesivas leyes de comunidades nativas (Decreto Ley 20653 de 1974, Decreto Ley 22175 de 1978 y sus reglamentos y directivas de menor rango) y del Código Civil, el gobierno peruano obliga a las comunidades nativas a elegir autoridades y acreditarlas mediante actas de asamblea que cumplan con la normatividad del Código Civil, entre otras normas. Esto se traduce en cargos antes desconocidos como presidentes, vice-presidentes, secretarios, tesoreros y vocales, lo que Gray llama "gobierno difuso" (2002, pp. $262,279)$.

En respuesta, los arakbut han venido designando como sus autoridades comunales mayormente a jóvenes que hablan mejor el español y manejan mejor los códigos culturales de la sociedad externa, como estrategia para defenderse frente al mundo externo. Estas autoridades no ostentan mayor prestigio al interior de sus comunidades, ni poder de decisión en sus comunidades. Ellas convocan a las asambleas comunales formales que se realizan en las casas comunales, que reemplazaron a las reuniones realizadas en el entorno de los fogones tradicionales. Sin embargo, las personas con mayor influencia en las decisiones internas de las comunidades siguen siendo los wa'iri. Las autoridades comunitarias formales asumen más un papel de carácter de ministros de relaciones exteriores que de presidentes ${ }^{4}$.

Esto no quiere decir que las autoridades comunales no abusan de sus cargos. Se dan casos de presidentes de comunidades nativas que han suscrito contratos

${ }^{4}$ Debo la calificación de "ministros de relaciones exteriores" al antropólogo peruano Luis Román Villanueva, (Comunicación personal, 1985). 
o acuerdos con mineros auríferos, madereros, representantes de compañías petroleras y otros sin el consentimiento de la comunidad o sin el consenso necesario. Incluso, cuando hay beneficios acordados a favor de las comunidades representadas, no han faltado situaciones en que las autoridades comunitarias han utilizado dichos beneficios a título personal o a favor de sus familias inmediatas sin dar cuenta a la asamblea de la comunidad, prácticas ajenas a la ética tradicional arakbut. Cuando esto se conoce, las asambleas comunales suelen cambiar y sancionar a las autoridades responsables.

Para evitar el conflicto, en las asambleas comunales actuales nadie habla en contra de la posición del presidente ni de otro orador. Más bien, cuando alguien no está de acuerdo con la agenda a tratarse, se ausenta. Por eso, es muy común que las asambleas no logren el quorum necesario. Cuando se trata de un contrato o convenio con alguna compañía petrolera, maderero o minero aurífero, a veces se aprueban con ocho o diez comuneros presentes, ya que la mayoría se abstuvo de participar. Dichos convenios o contratos carecen de legitimidad interna y externa, pero son aprovechados por los interesados en desmedro de los intereses de la comunidad.

Cuando la asamblea destituye a la autoridad responsable por un acuerdo inconveniente con foráneos, los cambios se dan por consenso tras discusiones sobre los méritos de los candidatos alternativos sin acusar directa ni públicamente a la autoridad en falta, ya que semejante acusación provocaría la defensa del acusado por los miembros de su clan y generaría un conflicto interno. Sin embargo, fuera de la asamblea se dan acusaciones entre miembros de diferentes clanes y la información circula de manera indirecta. Por su circulación indirecta, los chismes juegan en esto un papel importante para convencer a los miembros del clan de la autoridad en falta de apoyar a algún candidato alternativo, de manera que el cambio se da por consenso. Así, las autoridades se cambian con frecuencia.

Schuler Zea (2010) describe el mecanismo yesamarî (meandros o desvíos) en el diálogo entre los waiwai del norte de Brasil para no enfrentarse directamente. Esto me parece similar a lo que sucede entre los arakbut, aunque el proceso de éstos es menos ritual.

Una vez acreditada formalmente la autoridad comunal arakbut, su reemplazo es engorroso e implica viajes a la capital del departamento, Puerto Maldonado, para realizar los trámites correspondientes y hacer efectiva la decisión de la asamblea. La formalización de decisiones de las asambleas comunitarias ahora se realiza en el libro de actas de la comunidad que ha sido previamente abierto ante notario y que se tienen que transcribir y legalizar notarialmente para que se inscriban en los registros públicos. De otra manera no es considerado válido ante la justicia peruana. Cuando esto no se hace de acuerdo a las indicaciones del Código Civil, el 
cambio suele no ser reconocido por las autoridades del Estado o en negociaciones con entidades externas tales como compañías petroleras, madereras, entre otras, lo que ocasiona serios conflictos entre las partes interesadas.

Cuando se trata de un tema interno de la comunidad, la discusión se realiza en el idioma harakbut y las conclusiones y el consenso logrados se mantienen en forma oral. Pero cuando hay un conflicto con agentes externos y un acuerdo tomado, por ejemplo, entre los comuneros y mineros auríferos externos, dicha acta se registra por escrito en castellano y se obliga a las partes a firmarla.

Como hemos mencionado líneas arriba, los comuneros no se enfrentan ante sus parientes en las asambleas aún cuando están en desacuerdo con ellos. Por tanto, siguiendo sus patrones culturales tradicionales, los que perciben que su posición es minoritaria u opuesta por otra facción interna contraria no participan en las asambleas.

\section{EL PAPEL DE FENAMAD}

En enero de 1982, siete comunidades harakbut y una comunidad yine se reunieron en Boca del Karene para constituir la Federación Nativa del Río Madre de Dios y Afluentes (FENAMAD), una organización indígena que ha sido pluriétnica desde sus inicios y que ahora representa a todos los pueblos indígenas y sus 37 comunidades nativas de la cuenca del río Madre de Dios, en las regiones de Madre de Dios y Cusco. Además, defiende los derechos de los pueblos en aislamiento voluntario que, por su condición de tales, no integran formalmente la FENAMAD (Moore, 2015).

Los objetivos de FENAMAD son la defensa de los territorios y derechos de todos sus pueblos y comunidades bases frente a todos los actores externos, incluyendo autoridades y funcionarios, alcaldes, colonos, madereros, empresas de turismo, organizaciones no gubernamentales y toda otra instancia de la sociedad externa que afecte de alguna manera los intereses y la agenda política de sus comunidades integrantes 5 . Además, promueve el bienestar de los comuneros mediante intervenciones en educación, salud y desarrollo económico. FENAMAD no pretende ni tiene la capacidad de gobernar las comunidades que la integran, sino su representante ante los agentes tanto del Estado como de la sociedad no indígena.

FENAMAD ha podido negociar acuerdos con el gobierno nacional y el subnacional sobre aspectos de la minería aurífera, la extracción forestal, las áreas naturales protegidas y otros. Los alcaldes y las autoridades de los gobiernos subnacionales han brindado servicios de educación, salud y saneamiento, y han participado en algunos de los congresos de FENAMAD, recogiendo sus planteamientos. Las respuestas no han sido siempre satisfactorias, ya que la visión

${ }^{5}$ Enlace de su portal web: http://www.fenamad.com.pe/fenamad/. 
colonial sigue predominando entre estas autoridades y sus partidos políticos, incluso los que reclaman ser de "izquierda".

En el contexto del autodesarrollo de las comunidades locales y de su defensa territorial, FENAMAD ha intervenido en situaciones concretas que involucran a comunidades vecinas. Por ejemplo, para apoyar en la solución de conflictos entre las comunidades nativas del río Karene y mineros auríferos venidos de fuera, en mayo de 1992 FENAMAD organizó un encuentro de pueblos arakbut en Puerto Luz, donde tres comunidades vecinas tomaron la decisión de implementar una estrategia compartida sobre estos conflictos, además de otros puntos de la agenda (Gray, 2003). Este es uno de numerosos ejemplos de cómo FENAMAD, como representante de las comunidades y pueblos indígenas ante las instancias no indígenas, facilita acuerdos entre varias comunidades y asume sus propuestas ante los representantes del Estado.

En años más recientes, FENAMAD ha intervenido ante el Servicio Nacional de Áreas Naturales Protegidas (SERNANP) y su antecesor en la gestión de la Reserva Comunal Amarakaeri (RCA) en coordinación con las comunidades de su entorno. Hubo tensiones por decisiones tomadas a espaldas de las comunidades y sus organizaciones y que buscaban eliminar la zona de protección estricta de la RCA de manera que permitiera la entrada a esa área de Hunt Oil Company para la exploración de petróleo y gas.

FENAMAD reivindica a la RCA como territorio indígena, como era la intención en el momento de su propuesta de creación a través de la Ley Forestal y de Fauna Silvestre (Decreto Ley 21147) de 1975, mientras que SERNANP la considera suya como área natural protegida, bajo la posterior Ley de Áreas Naturales Protegidas (Ley 26835) de 1997. La administración, aunque no la gobernanza, de la RCA ahora corresponde al Ejecutor del Contrato de Administración de la Reserva Comunal Amarakaeri (ECA-RCA), liderada por un harakbut de la parcialidad wachiperi. Con el retiro de Hunt Oil del Lote 76 en 2017, por iniciativa de ECA-RCA, SERNANP aprobó un nuevo Plan Maestro que incluye áreas de protección estricta y cultural, reflejando mejor las prioridades de los arakbut.

\section{ESTRUCTURAS ORGANIZATIVAS ACTUALES}

La junta directiva de FENAMAD es elegida por períodos de cuatro años y en congresos a los cuales las comunidades integrantes envían tres delegados por comunidad. Los delegados deben ser elegidos en asambleas comunales y acreditados como tales. Esto no siempre ocurre de manera sistemática y transparente. Se han dado casos de delegados seleccionados por el presidente de la comunidad, y no por la asamblea, lo que es cuestionado por la asamblea o por el mismo congreso de FENAMAD. 
El último congreso de FENAMAD se realizó en la comunidad harakbut de Kotsimba, en enero de 2019. Allí se reeligió como presidente al comunero shipibo Julio Cusurichi Palacios, de la comunidad de El Pilar, cuya plancha incluye varios dirigentes nuevos y de diversos pueblos indígenas.

Desde 1985, el liderazgo de FENAMAD ha venido alternando en diferentes momentos entre dirigentes harakbut y de los otros pueblos, con rivalidad entre los candidatos. Por momentos, las tensiones generadas entre los dos bandos han amenazado la unidad de FENAMAD e incluso entre los mismos arakbut. A pesar de estas tensiones, hasta ahora FENAMAD ha podido mantener su unión con medidas para paliar las rivalidades, a diferencia de otras organizaciones indígenas de alcance regional de la Amazonía peruana.

Un mecanismo que ha empleado es la creación y reconocimiento de instancias intermedias: el Consejo Harakbut, Yine y Matsigenka (COHARYIMA) en la cuenca alta del Madre de Dios y el Consejo Indígena del Bajo Madre de Dios (COINBAMAD) en su cuenca baja. Además, FENAMAD ha establecido, como entidades técnicas, a la ECA-RCA y a la Asociación Forestal Indígena de Madre de Dios (AFIMAD) para atender las responsabilidades correspondientes a cada una.

En la Región Madre de Dios, FENAMAD ha venido coordinando estrechamente con la Federación Agraria Departamental de Madre de Dios (FADEMAD) y con los otros gremios productivos - de madereros, castañeros, mineros auríferos, entre otros. Durante la primera década de los 2000, se constituyó la Alianza de Federaciones, que en un momento incorporó también a la Federación de Mineros Auríferos de Madre de Dios (FEDEMIN). Las coordinaciones a través de la Alianza de Federaciones han sido intermitentes, especialmente en torno al tema de la minería aurífera, sobre la cual hay discrepancias de perspectivas. Las iniciativas más consolidadas de la Alianza han sido los sucesivos paros regionales para obtener de los gobiernos central y regional modificaciones de normas que perjudican a los integrantes de sus bases, tales como los controles de la gasolina y otras disposiciones que no se adecúan a la realidad en Madre de Dios y no han podido frenar la minería ilegal ni facilitar la formalización de los derechos de los interesados.

Desde sus inicios, FENAMAD ha estado afiliada a la Asociación Interétnica de Desarrollo de la Selva Peruana (AIDESEP). Sin embargo, cuando en 1988 se constituyó la Confederación de Nacionalidades de la Amazonía Peruana (CONAP) con disidentes de AIDESEP, FENAMAD la invitó a su VI Congreso de 1989 en la comunidad de Shintuya, donde, como estrategia para unir a las dos organizaciones nacionales, se aprobó tanto su afiliación a CONAP como la ratificación de su afiliación a AIDESEP. Este objetivo no fue logrado y futuras 
juntas directivas de FENAMAD abandonaron la iniciativa, reivindicando su filiación a AIDESEP y dejando de participar en eventos de CONAP.

AIDESEP ahora considera a FENAMAD como una de sus organizaciones regionales y también reconoce a COHARYIMA y COINBAMAD como federaciones de base. Así, en las asambleas de AIDESEP los pueblos indígenas de la cuenca del Madre de Dios cuentan con tres votos. Aun así, están en desventaja frente a las numerosas y fragmentadas organizaciones indígenas del Urubamba, Ucayali, Apurímac, Ene, Tambo, Perené, Gran Pajonal, Purús, Yuruá, Selva Central, los diferentes ríos de Loreto, San Martín y Amazonas, cada una de las cuales cuenta con un voto.

Así, FENAMAD se mantiene fuerte debido a su unión y su carácter pluriétnico. Además, tiene una larga trayectoria de manejo adecuado de fondos brindados por la cooperación internacional, a diferencia de otras organizaciones indígenas, y cuenta con el reconocimiento de esa fortaleza por parte de sus actuales y potenciales fuentes de financiamiento para sus actividades. Su debilidad es que, aún 37 años después de su organización inicial, no ha podido desarrollar mecanismos de autofinanciamiento de actividades, dependiendo de la cooperación internacional.

\section{LA PARTICIPACIÓN ELECTORAL}

Las elecciones nacionales, regionales y municipales no incorporan procedimientos que reflejan patrones tradicionales indígenas como el de los arakbut y, por tanto, no provocan mucho interés ni entusiasmo en dicho pueblo. Son vistos como asuntos ajenos a la realidad indígena. Desde sus inicios, FENAMAD ha venido definiendo e impulsando su agenda política ante los gobiernos nacional y subnacionales, y también ante los partidos políticos de Madre de Dios. Su marginación histórica se debe al limitado peso electoral de los comuneros que la integran, además del racismo predominante de los migrantes. Más aún, la visión política de las autoridades de gobierno y de los mismos partidos políticos ha sido y sigue siendo netamente colonial, con propuestas de dominio de los pueblos indígenas y no de su integración en igualdad de condiciones. Por tanto, la respuesta ha sido muy limitada y los intentos de acercamiento de parte de los partidos políticos ha sido extremadamente clientelista.

Hay excepciones. Por ejemplo, en las elecciones municipales para la provincia de Manu en el año 1989, la misión dominica de Shintuya, aliada con los intereses de los colonos, promovió la candidatura de un miembro del partido político Acción Popular, pues dicho candidato era "un buen cristiano" y cercano a los curas. Como estaba programado un congreso de FENAMAD ese ańo, días antes de las elecciones municipales, la propuesta de los directivos de FENAMAD fue convocar a todos los candidatos a presentarse ante el Congreso y exponer sus 
propuestas en relación con los pueblos indígenas, cuya población era mayoritaria en la provincia de Manu.

Casi todos los candidatos llegaron a presentar sus propuestas. El candidato de Acción Popular reivindicó sus buenas relaciones con la Iglesia Católica y, por tanto, su importancia para con los pueblos indígenas, pero su intervención fue recibida con silencio. Luego intervino el candidato del APRA, un maderero y comerciante de la zona, quien dijo: "todos ustedes me conocen y que soy su amigo." Esta intervención fue respondida con comentarios como "justamente porque te conocemos no te vamos a apoyar". Después intervino el candidato por la Izquierda Unida, un profesor de Salvación, la capital de la provincia, quien ofreció llevar a todas las comunidades nativas el programa del Vaso de Leche, una iniciativa del alcalde de Lima que era de su agrupación. La respuesta fue comentarios tales como "nosotros tomamos leche de nuestras madres hasta los tres años; después no tomamos más leche y, sobre todo, no tomamos leche de vaca". Finalmente, intervino el candidato de un partido minoritario, el Frente Nacional de Trabajadores y Campesinos (FRENATRACA), otro profesor de secundaria de Salvación y de origen puneño quien dijo "Yo soy indígena del pueblo aimara y siempre voy a apoyar a los pueblos indígenas. No tengo propuesta inmediata para la atención a los indígenas aquí en el Manu, pero si soy elegido todo lo que voy a hacer va a ser consultado y coordinado con ustedes y su organización y voy a respaldar sus propuestas." Recibió fuertes aplausos.

Las elecciones municipales se realizaron a los pocos días y el candidato del FRENATRACA ganó de manera sorpresiva y abrumadora gracias al voto indígena. Sirvió como alcalde de la provincia de Manu durante los tres años que le correspondieron y, efectivamente, realizó importantes coordinaciones con las comunidades harakbut, con otras de su provincia y con FENAMAD. Un logro importante para los arakbut fue la Resolución Municipal que respaldó la creación de la RCA.

En Madre de Dios no hubo ningún movimiento electoral similar al Movimiento Indígena de la Amazonía Peruana (MIAP) en Ucayali y la Selva Central en los años noventa. Algunos partidos políticos tradicionales, con el afán de captar votos en las comunidades nativas, buscaron, sin coordinación con FENAMAD, a indígenas para incorporarlos a sus listas de concejales, generalmente en posiciones hacia el final de la lista y sin opción de ganar.

Los arakbut participan poco en los procesos electorales debido a varias circunstancias. Algunos no tienen sus documentos nacionales de identidad (DNI) actualizados y no figuran en los registros de electores de sus distritos. Pero un número mayor no deja sus actividades productivas y familiares para emprender el largo viaje a la capital de su distrito, donde tendrían que llegar para sufragar. Por ejemplo, en el distrito de Madre de Dios de la provincia de Manu, 
la sede de la municipalidad donde se concentran las ánforas, se ubica en el centro poblado Boca Colorado, de población no originaria de Madre de Dios, mientras la mayor población arakbut está asentada en la Comunidad Nativa de Puerto Luz, a un día entero de distancia por río y con altos costos de combustible, cuya venta además está controlada como medida contra la minería ilegal y, por tanto, difícil de conseguir. La ruta alternativa por vía terrestre pasa por los principales centros comerciales que atienden a los mineros auríferos, con altos costos en pasajes.

Por tanto, el costo de ese viaje excede por mucho el valor de la multa por no sufragar. Tampoco sienten la necesidad de pagar las multas, por la gran distancia que los separa de la mayoría de las sedes de gobierno, bancos y otras entidades que podrían exigir el DNI con el sello del pago de la multa por no sufragar. Además, no ven la utilidad de escoger entre candidatos cuyas propuestas asumen una visión colonial.

En las elecciones para autoridades municipales, uno de los problemas es la cuota indígena establecida por la Ley 27734 del 2002. Mediante esta norma vigente, en su artículo $10^{\circ}$, inciso 3 , todos los partidos y movimientos políticos deben incluir, en sus listas en provincias y distritos donde existen comunidades nativas, no menos del 15\% de representantes de éstas (Espinosa, 2012; Paredes, 2015). Como resultado, todos los partidos y movimientos políticos en Madre de Dios incluyen a candidatos indígenas para el cargo de concejales (Espino, 2012). Este requisito divide el voto indígena por líneas de parentesco con los candidatos, de manera que pocos son elegidos y hay pocas posibilidades de elegir alcaldes indígenas.

En las elecciones subregionales de Madre de Dios en el 2010, un arakbut de la comunidad de Shintuya fue elegido concejal en la provincia de Manu, donde fue vocero importante de los intereses de las comunidades nativas. En las mismas elecciones fue elegida consejera regional la arakbut de Shintuya, Luz Bario, de otra lista electoral. A pesar de su limitada preparación previa y su selección a dedo por el partido que la lanzó, sin coordinación con su comunidad ni con FENAMAD, tuvo una gestión bastante respetable. Luego, en las elecciones municipales del 2014, una arakbut de Shintuya residente en Puerto Maldonado fue elegida concejal en la provincia de Tambopata, también haciendo un papel respetable.

En las elecciones nacionales del 2016, sólo un partido político, Acción Popular, lanzó un candidato indígena para el Congreso: Janet Corisepa Neri, una harakbut de la comunidad de Puerto Azul. Ni siquiera el partido del candidato shipibo a la presidencia de la República, Miguel Hilario Escobar, incluyó indígenas en su lista de candidatos al Congreso por Madre de Dios. Algunos shipibos simpatizaban con su paisano Hilario. Sin embargo, en 
conversaciones con los dirigentes de FENAMAD, capté mayor simpatía con la campaña de Verónika Mendoza, del Frente Amplio, cuya plataforma incorporaba importantes propuestas de los pueblos amazónicos.

Es evidente que los procedimientos electorales peruanos no son consistentes con la visión y las prácticas de política indígena y, por tanto, allí donde se da la participación indígena es mecánica y no apropiada para los arakbut ni para los otros pueblos indígenas de Madre de Dios.

Hay una imperiosa necesidad de reformar las leyes electorales antes de los próximos comicios para evitar la confusión actual e incluir a los pueblos indígenas de manera más justa. Entre las medidas propuestas será importante la derogatoria de la Ley 27734 y su reemplazo con una norma más adecuada que facilite a los pueblos indígenas de la selva la posibilidad de lanzar sus propios partidos y movimientos políticos para que se presenten unidos en las elecciones subnacionales. Además, sería sumamente importante que las leyes electorales permitan la instalación de mesas de sufragio en las mismas comunidades nativas, no solamente en la capital distrital que está alejada de estas.

Otra propuesta alternativa interesante sería que, en las elecciones al Congreso, se establezca un distrito electoral autónomo con una cuota de curules reservada para los pueblos indígenas de la selva, sin que tengan que adherirse a los partidos y movimientos políticos tradicionales (Espinosa, 2012).

Mientras tanto, los arakbut siguen marginados de los gobiernos que definen las políticas que afectan a sus intereses, mientras que las políticas de carácter colonial y vertical en torno a sus intereses persisten.

\section{Conclusiones}

Vemos que los arakbut mantienen muchos elementos de su visión y prácticas políticas tradicionales, según del modelo de Clastres, especialmente la no confrontación entre sí y el alejamiento dentro del territorio mayor de las facciones disidentes. El liderazgo para asuntos netamente internos todavía es ejercido por los wa'iri, los sabios mayores. Sin embargo, en el trato con la gente y las instituciones externas, las expresiones políticas reflejan una combinación de los valores tradicionales con las desviaciones de ellos aprendidos por los jóvenes a través de sus relaciones con los mestizos. La tensión entre estas diferentes perspectivas refleja serias crisis de identidad aún no resueltas en muchos individuos.

Sin embargo, la generación joven de líderes arakbut de las organizaciones políticas indígenas de Madre de Dios, como FENAMAD, COHARYIMA, ECA-RCA y ahora la Nación Harakbut, demuestra su afirmación étnica como 
el valor más importante en un proceso de etnogénesis que enfrenta a los valores destructivos de su cultura. Estas organizaciones reflejan lo que Gray llama gobierno difuso, pero que, en mi interpretación, responden más a la necesidad de tratar con las fuerzas externas de la cultura arakbut en términos que ayuden a defender sus intereses, antes que una expresión política o de gobernanza propia.

A diferencia de mis interpretaciones de hace 40 años, ahora soy más optimista; estoy convencido de que vamos a ver nuevas generaciones de arakbut que reivindiquen su identidad y con ella, su visión y prácticas políticas como parte de los cambios nacionales y globales que deben darse entre los pueblos en el futuro.

Hasta ahora, la participación arakbut en los procesos políticos nacionales es limitada y fragmentada, sin visión clara de proyección al futuro. Los arakbut la consideran ajena a sus intereses. Esperamos que se den cambios tanto en las políticas nacionales para su inclusión más equitativa como iniciativas propias innovadoras de parte de los arakbut.

\section{REFERENCIAS}

Adelaar, Willem F. H. (2000). Propuesta de un nuevo vínculo genético entre dos grupos lingüísticos de la Amazonía occidental: Harakmbut y Katukina. En Luis Miranda (Ed.), Actas I Congreso de Lenguas Indígenas de Sudamérica, tomo 2 (pp. 219-236). Lima: Universidad Ricardo Palma, Facultad de Lenguas Modernas, Departamento Académico de Humanidades.

Adelaar, Willem F. H. (2007). Ensayo de clasificación del Katawixí dentro del conjunto Harakmbut-Katukina. En Andrés Romero Figueroa, Ana Fernández Garay y Ángel Corbera Mori (Eds.), Lenguas indígenas de América del Sur: Estudios descriptivo-tipológicos y sus contribuciones para la lingüistica teórica (pp. 159-169). Caracas: Universidad Católica Andrés Bello.

Álvarez del Castillo, Juan Alex (2012). La propiedad compleja: Gobernanza de la tierra y conservación en la Amazonía. La Reserva Comunal Amarakaeri, Madre de Dios, Perú [Tesis doctoral, Institut de Hautes Études Internationales et du Développment, Geneva]

Clastres, Pierre (1974). La société contre l'état. París: Éditions Minuit.

Diamond, Stanley (1974/1993). In Search of the primitive: A critique of civilization. Londres: Transaction Publishers.

Espino Cortés, Hernán (2012). En torno a la aplicación de la cuota electoral indígena. Reflexiones desde la jurisprudencia del Jurado Nacional de Elecciones, procesos 2006-2010. En Alicia del Águila y Milagros Suito (Eds.). Participación electoral indigena y cuota nativa en el Perú: Aportes para el debate (pp. 73-80). Lima: Instituto Internacional para la Democracia y la Asistencia Electoral [IDEA], Jurado Nacional de Elecciones [JNE]. 
Espinosa, Óscar (2012). El sistema de cuota electoral indígena en la Amazonía: Problemas y limitaciones. En Alicia del Águila y Milagros Suito (Eds.). Participación electoral indigena y cuota nativa en el Perú: Aportes para el debate (pp. 37-46). Lima: Instituto Internacional para la Democracia y la Asistencia Electoral [IDEA], Jurado Nacional de Elecciones [JNE].

Federación Nativa del Río Madre de Dios y Afluentes [FENAMAD] (2015). Los harakbut, su territorio y sus vecinos. Peritaje antropológico presentado al Tribunal Constitucional del Perú en el litigio entre los representantes del pueblo harakbut. Lima: FENAMAD y Hunt Oil Company.

Göhring, Hermann (1887/2006). Informe al Supremo Gobierno del Perú sobre la expedición a los valles de Paucartambo en 1873 al mando del Coronel d. Baltazar La-Torre. En Alberto Chirif (Ed.), Exploraciones de los ríos del sur (pp. 313-459). Iquitos: Centro de Estudios Teológicos de la Amazonia [CETA].

Gray, Andrew (1997/2002). Derechos indigenas y desarrollo: Autodeterminación en una comunidad amazónica. Lima: Grupo Internacional de Trabajo sobre Asuntos Indígenas [IWGIA].

Gray, Andrew (2003). Gobierno indígena en Madre de Dios. En Beatriz Huertas Castillo y Alfredo García Altamirano (Eds.), Los pueblos indígenas de Madre de Dios: Historia, etnografía y coyuntura (pp. 382-388). Lima: Grupo Internacional de Trabajo sobre Asuntos Indígenas [IWGIA].

Hindess, Barry y Hirst, Paul Q. (1975). Pre-capitalist modes of production. Londres: Routledge \& Kegan Paul.

Huertas Castillo, Beatriz (2002). Los pueblos indigenas en aislamiento: su lucha por la sobrevivencia y la libertad. Lima: Grupo Internacional de Trabajo sobre Asuntos Indígenas [IWGIA].

Huertas Castillo, Beatriz (2003). La extracción forestal y los pueblos indígenas en aislamiento de Madre de Dios. En Beatriz Huertas Castillo y Alfredo García Altamirano (Eds.), Los pueblos indígenas de Madre de Dios: Historia, etnografía y coyuntura, (pp. 353-373). Lima: Grupo Internacional de Trabajo sobre Asuntos Indígenas [IWGIA].

Huertas Castillo, Beatriz (2010). Despojo territorial, conflicto social y exterminio. Pueblos indígenas en situación de aislamiento, conflicto esporádico y contacto inicial en la Amazonía peruana (informe No. 9, Grupo Internacional de Trabajo sobre Asuntos Indígenas). Lima.

Jaulin, Robert (1970). La paix blanche: Introducción a l'ethnocide. Paris: Combats Seuil.

Mair, Lucy (1962). Primitive government. Baltimore: Penguin Books.

Meillassoux, Claude (1975/1977). Mujeres, graneros y capitales. México: Siglo XXI.

Moore, Thomas (2003). La etnografía tradicional Harakbut y la minería aurífera. En Beatriz Huertas Castillo y Alfredo García Altamirano (Eds.), Los pueblos 
indigenas de Madre de Dios: Historia, etnografía y coyuntura (pp. 58-90). Lima: Grupo Internacional de Trabajo sobre Asuntos Indígenas [IWGIA].

Moore, Thomas (2006). Introducción. En Alberto Chirif (Ed.), Exploraciones de los ríos del sur (pp. 15-73). Iquitos: Centro de Estudios Teológicos de la Amazonia [CETA].

Moore, Thomas (2015). Los orígenes de la FENAMAD y el proceso de consolidación territorial de las comunidades nativas en Madre de Dios. Estructura Salvaje, (4), 60-80.

Olivera, José María (1907) Informe del jefe de la comisión exploradora del alto Madre de Dios por la vía de Puerto Maldonado. La Opinión Nacional, pp. 395-439.

Paredes, Maritza (2015). Representación politica indígena: Un análisis comparativo subnacional. Lima: Jurado Nacional de Elecciones, IDEA Internacional, Vice-Ministerio de Interculturalidad del Ministerio de Cultura, Instituto de Estudios Peruanos.

Parellada, Alejandro (Ed.). (2007). Pueblos indígenas en aislamiento voluntario y contacto inicial en la Amazonía y el Gran Chaco. Seminario Regional de Santa Cruz de la Sierra, Bolivia.

Perrone-Moisés, Beatriz; Sztutman, Renato y Cardoso, Sérgio (eds.). (2011). Dossiê Pensar com Pierre Clastres. Revista de Antropologia, 54(2). http://www. revistas.usp.br/ra/issue/view/3336

Pinedo, Danny David (2014). The politics of sociality: Social networks and indigenous mobilization in Peruvian Amazonia [Tesis doctoral, Universidad de Florida, Gainesville].

Schuler Zea, Evelyn (2010). On-yesamarî and laterality: waiwai meanderings. Tipiti: Journal of the Society for the Anthropology of Lowland South America, $8(1)$. https://digitalcommons.trinity.edu/cgi/viewcontent. cgi?article $=1112 \&$ context $=$ tipiti

Torralba Serrano, Adolfo (1979/2014). Los Harakmbut: nueva situación misionera. En Rafael Alonso Ordieres y Miguel Ángel Fernández Alonso (Eds.), Honor y liberación: Historia contemporánea del pueblo harakmbut: Relatos y análisis desde la mirada de los misioneros dominicos (pp. 581-597). Lima: Centro Cultural José Pío Aza. 